\title{
Estimation of effective diffusivity of pear tissue and cuticle by means of a numerical water diffusion model
}

\author{
T.A. Nguyen ${ }^{\mathrm{a}, *}$, P. Verboven ${ }^{\mathrm{a}}$, N. Scheerlinck ${ }^{\mathrm{a}}$, Stefan Vandewalle ${ }^{\mathrm{b}}$, Bart M. Nicolaï ${ }^{\mathrm{a}}$ \\ a Flanders Centre/Laboratory of Postharvest Technology, Agro-Engineering and Economics, Katholieke Universiteit Leuven, \\ $W$. de Croylaan 42, B-3001 Leuven, Belgium \\ b Scientific Computing Research Group, Computer Science Department, Katholieke Universiteit Leuven, Celestijnenlaan 200A, B-3001 Leuven, Belgium
}

Received 9 June 2004; accepted 8 November 2004

Available online 22 December 2004

\begin{abstract}
An estimation procedure of effective diffusivity in pear tissue by means of a numerical water diffusion model is presented. Conference pears (Pyrus communis cv. Conference) of different picking date and different storage period and temperature were investigated. The moisture diffusivity of different tissues like outer cortex, inner cortex and cuticle was estimated. Results showed that the effective diffusion coefficients of water are slightly larger in late picking date pears than those of early picking date, but the effect of storage time was unclear and a large biological variability was observed. Temperature had different effects on the different tissues. The diffusion coefficients increased by a factor 2 in case of cuticle and by a factor 3.6-9.6 in the case of inner cortex tissue when the temperature increased from $1^{\circ} \mathrm{C}$ to $20^{\circ} \mathrm{C}$. The value of the diffusion coefficient decreased dramatically from inner cortex tissue $\left(123.0 \times 10^{-13} \mathrm{~m}^{2} \mathrm{~s}^{-1}\right.$ at $1^{\circ} \mathrm{C} ; 435.9 \times 10^{-13} \mathrm{~m}^{2} \mathrm{~s}^{-1}$ at $\left.20^{\circ} \mathrm{C}\right)$ to outer cortex tissue $\left(5.3 \times 10^{-13} \mathrm{~m}^{2} \mathrm{~s}^{-1}\right.$ at $1^{\circ} \mathrm{C} ; 10.5 \times 10^{-13} \mathrm{~m}^{2} \mathrm{~s}^{-1}$ at $\left.20^{\circ} \mathrm{C}\right)$ and cuticle $\left(0.55 \times 10^{-13} \mathrm{~m}^{2} \mathrm{~s}^{-1}\right.$ at $1{ }^{\circ} \mathrm{C}$ and $1.28 \times 10^{-13} \mathrm{~m}^{2} \mathrm{~s}^{-1}$ at $\left.20^{\circ} \mathrm{C}\right)$. These values are comparable with those in literature obtained for other horticultural products such as apple.
\end{abstract}

(C) 2004 Elsevier Ltd. All rights reserved.

Keywords: Continuum; Sorption isotherm; Moisture transfer; Diffusion; Cuticle; Pear

\section{Introduction}

In fruits, water is one of the most important components to provide in their metabolic, nutritional, physiological and biochemical needs. The water content in plants varies according to species, tissue and cell type and is also dependent on ambient and physiological conditions (Merva, 1995).

Moisture transport in fruit has been modelled by means of Fick's second law of diffusion. Three mechanisms are often considered most dominant in foods in general: convection (Darcy flow), molecular diffusion

\footnotetext{
${ }^{*}$ Corresponding author. Tel.: +32 16 321453; fax: +32 16322955

E-mail address: anh.nguyen@agr.kuleuven.ac.be (T.A. Nguyen).
}

and capillary diffusion (Datta \& Zhang, 1999). They differ according to the driving force, which causes the movement. Convection occurs by a pressure difference. The second mechanism is driven by a concentration difference. The last mechanism is due to the difference between the relative attraction of the molecules of the liquid for each other and for those of the solid. Moisture transport studies in conventional heating and conventional drying often use an effective diffusivity model encompassing all these terms to some extent (Datta \& Zhang, 1999). In fruit, transport also occurs by osmosis. Osmosis is a combination of pressure and diffusion flow across selective cell membranes (Finkelstein, 1987). The continuum approach to mass transfer is the simplest means to describe moisture diffusion in fruit tissue because it avoids the necessity of modelling the 
microscopic pore space. It constitutes a phenomenological approach as the mass transfer coefficients that appear in the macroscopic balances have to be determined experimentally. However, such models, in which moisture fluxes are expressed in terms of water concentration gradients, hide the complex water relations and underlying transport processes in the cellular tissue (Datta, 2002). Clearly, water content alone is insufficient to describe water status and movement in fruit, in relation to cellular disorders that result in quality loss (Nguyen, Verboven, Daudin, Vandewalle, \& Nicolaï, 2004).

In literature, the published data of moisture diffusivity in food products present a huge variability and the values vary from $10^{-12}$ to $10^{-8} \mathrm{~m}^{2} / \mathrm{s}$ (Zogzas, Maroulis, \& Marinos-Kouris, 1996). This variability depends on the types and conditions of experimental procedures used for determination of the moisture diffusivity, data treatment methods (Zogzas \& Maroulis, 1996) as well as on the product properties (composition, physiological state, heterogeneity of the structure) (Gou, Mulet, Comaposada, Benedito, \& Arnau, 1996).

Moisture diffusivity in solid foods can be determined by different methods involving defined geometries, and well-defined experimental conditions (steady state or transient conditions). The methods, which have been used to estimate water diffusivity are based on drying kinetics, sorption or desorption kinetics, and moisture profile analysis (Crank, 1975; Doulia, Tzia, \& Gekas, 2000; Gros \& Ruegg, 1987; Zogzas \& Maroulis, 1994). The most frequently used methods for moisture diffusivity for solid foods are briefly presented here.

\subsection{Permeation method}

A thin sheet of solid is kept in between two compartments which are conditioned at constant but different humidity and temperature. After a certain time, a steady state is reached and a constant linear concentration gradient is developed in the material and the surfaces of the thin sheet are assumed in equilibrium with the diffusion source. The diffusivity (or permeability) is deduced from an observed value of the rate of moisture transfer (by a balance) and the known concentration in two compartments (Crank, 1975). The major difficulty of the experiment is to set up and to maintain the steady state conditions. Most authors also neglect to take into account the presence of boundary layers on both sides of the sample which change the partial pressure at the surface and distort the determined value of diffusivity.

\subsection{Sorption/desorption and drying method}

The weight of the sample with a well-defined geometry is measured at regular times to evaluate the moisture uptake (in sorption cases) or the moisture loss (in desorption or drying cases) until the final equilibrium is reached. The diffusivity can be calculated from the changing concentration plotted as a function of time (Crank, 1975). The largest difficulty of this drying procedure is to maintain a constant ambient concentration during the experiment. Samples often shrink, as a consequence of which the moisture diffusivity varies with the moisture content. It is important to notice that this method is again based on the assumption that the external resistance to moisture transfer is negligible, which is not always proven.

\subsection{Concentration-distance curve method}

The moisture concentration profile within the sample as a function of distance during a one-dimensional unsteady state diffusive process is identified at a certain time. A cylinder of material, containing an initial uniform moisture concentration is place in contact with an environment maintained at lower concentration. The diffusion occurs along the axis of the cylinder (Veraverbeke, Verboven, Scheerlinck, Hoang, \& Nicolaï, 2003). After a period of time, the moisture concentration along this axis can be determined by slicing and weighing the samples. An alternative method of high resolution is magnetic resonance imaging; it also allows a non-destructive measurement of moisture profiles (Ruiz-Cabrera, Gou, Foucat, Renou, \& Daudin, 2004; Verstreken, Van Hecke, Scheerlinck, De Baerdemaeker, \& Nicolaï, 1998).

By the above methods, diffusivity can be identified from experimental data using analytical or numerical solutions of Fick's law of diffusion. The numerical method by finite elements is of great interest in multi-dimensional phenomena but is also a fast and accurate alternative for the other methods for a 1-D case. Numerical methods are not restricted to specific geometries or boundary conditions like analytical ones. In fact there is no standard method for evaluating diffusivity. The choice of the experimental procedure depends on the particular needs of the experiment.

The objective of this work was to estimate the apparent diffusion coefficient of water in different tissues of pear. In the experiment, the driving force was a difference in chemical potential, rather than concentration gradients. The effective diffusivity of cuticle and cortex tissues was estimated with Fick's first and second law, respectively. The latter was solved by means of the finite element method. In article, the effects of picking date, storage period and shelf life temperatures will be investigated.

\section{Materials and methods}

\subsection{Fruits}

Conference pears (Pyrus communis cv. Conference) were picked at commercial picking date, one week 
before and one week after commercial picking date. The commercial picking date for Belgium was determined by the Flanders Centre of Postharvest Technology, Leuven, Belgium (Anonymous, 2003), based on a comparison of refractometer values, starch index, acidity and Magness-Taylor firmness with historical data (in September, 2002). At each picking date, all pears from four trees were harvested. The pears were cooled to $1{ }^{\circ} \mathrm{C}$ for three weeks in normal air, then stored under controlled atmosphere conditions $\left(2.5 \% \mathrm{O}_{2}, 0.7 \% \mathrm{CO}_{2}\right.$ at $-1{ }^{\circ} \mathrm{C}$ and $\pm 95 \% \mathrm{RH}$ ) during the investigation period in accordance with commercial practice.

During the shelf life time (at $20^{\circ} \mathrm{C}$ and $\pm 90 \% \mathrm{RH}$ ), the firmness loss and sugar content change were also followed. The firmness tests were performed on two opposite sides of fruits by means of a TAXT2 universal testing machine (Stable Micro System Ltd., Godalming, Surrey, England, UK), using a $10 \mathrm{~mm}$, diameter cylindrical probe and loading at $8 \mathrm{~mm} / \mathrm{s}$ until rupture. The sugar content was measured by means of a digital refractometer (PR-101, Atago Co., Ltd., Japan) on each of 15 pears for each date. The water transport in different tissues of pear was investigated.

\subsection{Samples}

Different tissues (inner, outer cortex and cuticle) of an intact pear were investigated. The pear core was not included in the investigation. Different samples were used in four different experiments.

In experiments 1 and 2, two identical tissue cylinders (20 $\mathrm{mm}$ length, $22 \mathrm{~mm}$ diameter) were obtained from the whole fruit at the equatorial position with a cork borer. For experiment 1, a layer of $5 \mathrm{~mm}$ which contains outer cortex tissue and cuticle was removed from the sample that contained only inner cortex. In experiment 2 , only the cuticle was mechanically removed by scratching a very sharp blade over the fruit surface, so the sample contained both inner and outer cortex. At macro-scale, damaging of the cells on the surface was neglected. In the both cases, one of the cylinders (diffusion sample) was used for the diffusion measure- ment and the other (initial sample) for the determination of the initial radial profile of moisture content existing in the pear.

In experiment 3, a layer of approximately $0.3 \mathrm{~mm}$ was first mechanically separated from pear tissue by a knife. A round piece $(\sim 30 \mathrm{~mm}$ diameter $)$ of this layer which contains cuticle and outer cortex tissue was used as a sample in the experiment 3 .

In order to get the cuticle only (experiment 4), the remaining tissue in the sample of previous experiment was removed by deeply shaking in an enzymatic solution (pectinase $2 \%$, cellulase $0.2 \%$ ) at a speed of $100 \mathrm{rpm}$ on a shaker (HAAKE SWB20, Germany) at $37^{\circ} \mathrm{C}$ for $5 \mathrm{~h}$. The separated cuticle was finally washed and kept in distilled water at $1{ }^{\circ} \mathrm{C}$ in a cool room.

\subsection{Experiment set-up}

For measuring water diffusion in pear tissues and cuticle, two set-ups (A and B) were installed, which used pear tissue cylinders (experiments 1 and 2) or skin layers (experiments 3 and 4) depending on whether the respective water diffusion in the tissue layers or across the skin had to be measured.

\subsubsection{Set-up A}

A polyvinylchloride $(\mathrm{PVC})$ container $(5.5 \mathrm{~cm}$ height and $4 \mathrm{~cm}$ diameter) with an inner volume of $50 \mathrm{ml}$ was sealed with a screw cap (Fig. 1a) containing a second concentric PVC cylinder $(2.2 \mathrm{~cm}$ diameter $)$ in which a pear tissue sample with diameter of $2.2 \mathrm{~cm}$ and maximum length of $2.5 \mathrm{~cm}$ is positioned. An aeration pinhole was made in the screw cap to prevent the development of pressure inside the system upon closure. The pinhole was sealed with mastic before measurement (Veraverbeke et al., 2003).

\subsubsection{Set-up $B$}

A polyvinylchloride (PVC) container $(6.5 \mathrm{~cm}$ height and $4 \mathrm{~cm}$ diameter) was sealed with a hollow screw cap (hole of $2.5 \mathrm{~cm}$ diameter). The topside of the container had also a hole like that in the screw cap
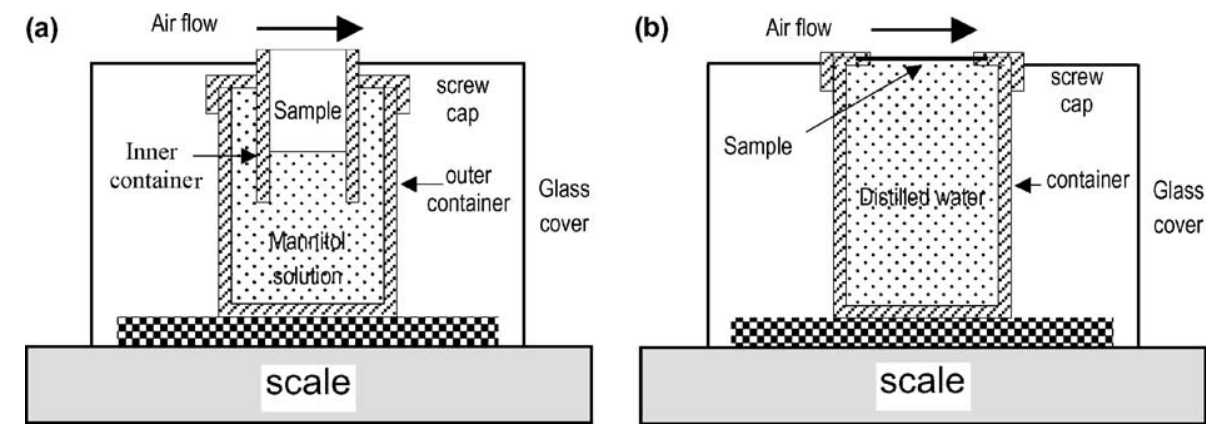

Fig. 1. Diffusion experimental set-up: (a) Veraverbeke et al. (2003) and (b) Nguyen et al. (2002). 
(Fig. 1b). The sample slice was kept in between the screw cap and the top side of the container (Nguyen, Verboven, Scheerlinck, Veraverbeke, \& Nicolaï, 2002).

In both set-ups, the weight loss due to diffusion of water was then recorded as a function of time. The container with sample was, therefore, placed on a balance (Sartorius, P1200S, Germany) with a glass draft shield cylinder and draft shield cover to eliminate the disturbing effect of air flow on the measurement accuracy. Only the top of the container, which contained the exposed pear tissue surface or pear cuticle, was in contact with the surrounding air through a hole in the draft shield cover. The balance was connected to the computer and the weight was recorded every minute over the experimental period. The graphical user interface was programmed in LABVIEW 5 (National Instrument, Zaventem, Belgium). To provide high mass transfer coefficients, a continuous airflow $\left(1 \pm 0.1 \mathrm{~m} \mathrm{~s}^{-1}\right)$ was applied over the sample surface by means of a fan system. The whole set-up with the balance and fan system was placed inside a cooling room at set temperature and relative humidity in complete darkness. The exact $\mathrm{RH}$ and temperature were measured additionally by means of Escort Junior loggers (Escort, Techinovators, New Zealand, $\left.\pm 0.1{ }^{\circ} \mathrm{C}, \pm 0.2 \% \mathrm{RH}\right)$.

\subsubsection{Moisture concentration profiles vs. water potential profiles}

The moisture profile of a pear tissue cylinder after diffusion together with the initial moisture profile from an identical cylinder of the same fruit was determined (experiments 1 and 2). Every cylinder was cut into slices, starting at the physical outer side of the cylinder. The exact thickness of every slice was determined with a digital calliper (Mitutoyo Ltd, UK, $\pm 0.01 \mathrm{~mm}$ ) and the weight of every slice, before and after drying at $105^{\circ} \mathrm{C}$ for $48 \mathrm{~h}$, was determined on an analytical balance (Sartorius BP 160P, Germany). Moisture profiles were determined as moisture content $(\mathrm{kg} / \mathrm{kg})$ on dry weight basis as a function of position in the pear tissue cylinder (m). These profiles were then transformed into water potential profiles by means of sorption isotherms of both outer cortex and flesh tissues. Sorption isotherms were obtained previously (Nguyen et al., 2004). In that study, a comprehensive investigation of sorption isotherms in the high RH range (80-100\%) was carried out at 1 and $18.5^{\circ} \mathrm{C}$ for different parts (inner cortex, outer cortex tissues and cuticle) of early and late picked Conference pears after 1 month and 6 months of storage in controlled atmosphere conditions.

\subsection{Diffusion model}

In this phenomenological approach, comparative to Fick's first law, water diffuses as a consequence of a gradient in water potential (Nobel, 1991):
$J=-K \nabla \psi$

with $J$ the moisture flux $\left(\mathrm{kg} \mathrm{m}^{-2} \mathrm{~s}^{-1}\right), K$ the moisture conductivity of the medium $\left(\mathrm{kg} \mathrm{m}^{-1} \mathrm{~Pa}^{-1} \mathrm{~s}^{-1}\right), \psi$ the water potential $(\mathrm{Pa})$ and $\nabla$ the gradient operator. It is assumed here that different tissues have distinct $K$ values. This model can be used to estimate the diffusion coefficient of a thin layer when a steady state is reached and a constant linear concentration gradient is developed in the material. Diffusivity (or permeability) is deduced from an observed value of the rate of moisture transfer and the known concentration in two compartments (experiments 3 and 4).

For a thick cylinder, moisture transport is described by means of Fick's second law:

$\rho_{\mathrm{dm}} c_{\psi} \frac{\partial C}{\partial t}=\nabla K \nabla C$

or

$\rho_{\mathrm{dm}} c_{\psi} \frac{\partial \psi}{\partial t}=\nabla K \nabla \psi$

with $\rho_{\mathrm{dm}}$ the dry matter density $\left(\mathrm{kg}_{\mathrm{dm}} \mathrm{m}^{-3}\right), C$ the moisture content on dry base $\left(\mathrm{kg} \mathrm{kg}_{\mathrm{dm}}^{-1}\right), c_{\psi}$ the moisture capacity $\left(\mathrm{kg} \mathrm{kg}_{\mathrm{dm}}^{-1} \mathrm{~Pa}^{-1}\right)$ and $t$ the time (s). The moisture capacity can be derived from the sorption isotherm curve:

$c_{\psi}=\frac{\partial C}{\partial \psi}$

and is a function of the tissue type (Nguyen et al., 2004).

Over small ranges of moisture contents, $c_{\psi}$ is constant Eqs. (2) then become:

$\frac{\partial C}{\partial t}=\nabla D \nabla C$

$\frac{\partial \psi}{\partial t}=\nabla D \nabla \psi$

where moisture diffusivity $D\left(\mathrm{~m}^{2} \mathrm{~s}^{-1}\right)$ equals:

$D=\frac{K}{\rho_{\mathrm{dm}} c_{\psi}}$

The one-dimensional, linear version of Eqs. (2) in terms of concentrations is used for this specific mass transfer problem with boundary conditions:

at $x=0$ :

$-D \frac{\partial C}{\partial x}=h\left(C-C_{\infty}\right)$

$-D \frac{\partial \psi}{\partial x}=h\left(\psi-\psi_{\infty}\right)$

And at $x=L$ :

$C=C_{0}$

$\psi=\psi_{0}$ 
and initial conditions:

$C(x, t)=C_{1}(x)$ at $t=0$

$\psi(x, t)=\psi_{1}(x) \quad$ at $t=0$

with $h$ is the mass transfer coefficient $\left(\mathrm{m} \mathrm{s}^{-1}\right) . C_{\infty}$ and $\psi_{\infty}$ are the moisture concentration and water potential of a pear tissue, which is in equilibration with the environment $\left(\mathrm{kg} \mathrm{kg}_{\mathrm{dm}}^{-1}\right)$, derived from sorption isotherm. $C_{1}(x)$ and $\psi_{1}(x)$ are known functions which are determined experimentally from original pear samples and $\psi=\psi(C)$ according to the sorption isotherm characteristics (Nguyen et al., 2004). $L$ is the length of sample. Typically a moisture profile across the pear cylinder could be considered as the sum of a linear and an exponential function. The following equation was used to fit the initial profiles of the moisture content in pear samples. Subsequently this fit was used as the initial condition in the estimation procedure.

$C=C_{0}+a x+\left(C_{\infty}-C_{0}\right)(1-\exp (-k x))$

where $C_{0}, C_{\infty}, a$ and $k$ were fitted to measured profiles. A similar operation was used for water potential profiles.

In samples with different tissues, a formulation based on water potential is required. In samples of inner cortex only, both formulations are valid.

\subsection{Finite element formulation}

In the framework of the finite element method the continuum is subdivided into quadratic finite elements. By application of the Garlerkin weighted residual method, the diffusion equation was discretised in space, which results in the following linear equations (Segerlind, 1984):

$\mathbf{C} \frac{\mathrm{d}}{\mathrm{d} t} \mathbf{u}+\mathbf{K u}=\mathbf{f}$

and

$\mathbf{u}_{(t=0)}=\mathbf{u}_{0}$

with $\mathbf{u}=\left[\begin{array}{llll}u_{1} & u_{2} & \ldots & u_{n}\end{array}\right]^{\mathrm{T}}$ the overall nodal water potential vector, $\mathbf{C}$ the capacitance matrix and $\mathbf{K}$ the conductance matrix, both $n \times n$ matrices, and $\mathbf{f}$ the finite element load vector, an $n \times 1$.

For the 1-D diffusion of water through the longitudinal axis of a pear tissue cylinder (experiment 1), the model consisted of one single material (inner cortex) meshed into 50 two-nodal isoparametric quadrilateral elements, with a gradual refinement from one end $(x=L)$ to another $(x=0)$, resulting in a total of 51 nodes. For estimation of the diffusion coefficients of the outer cortex tissue a sample of both inner and outer cortex tissue was used for which the finite element model consisted of two materials (experiment 2). The grid for the first material (inner cortex) was identical to the

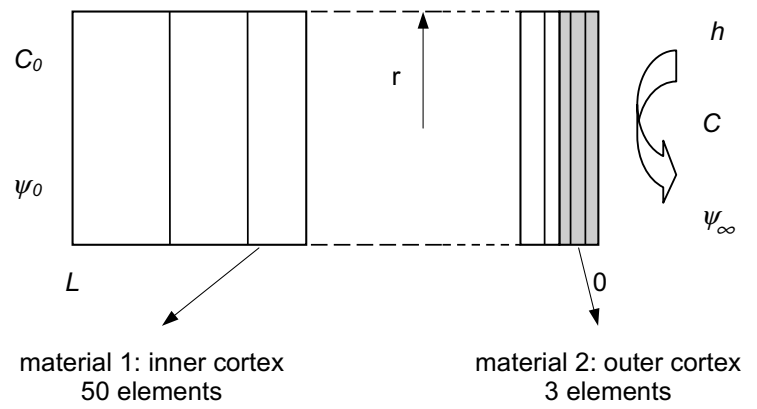

Fig. 2. Two-material finite element model for one-dimensional diffusion of water in pear tissue cylinder. The first material (inner cortex) is meshed into 50 elements and the second (outer cortex) into three elements with a gradual refinement of the mesh from inside $(L)$ to surface $(0)$

one used for the one material approach. The grid for the second material consisted of three additional element without refinement toward the outer surface, resulting in a total of 53 elements and 54 nodes over the whole cylinder (Fig. 2). The refinement study showed the grid was sufficiently dense. Eq. (10) was solved by means of an implicit Euler scheme.

\subsection{Parameter estimation}

\subsubsection{Mass transfer coefficients}

Using Eq. (6), mass transfer coefficients $(h)$ were determined from flux measurements in combination with known relative humidity $(\mathrm{RH})$ of the environment and with known surface moisture content of the tissue. Fluxes across the known surface of the sample were measured by means of a balance (Sartorius, P1200, Germany). The temperature and relative humidity were measured by means of Escort loggers (Escort, Techinnovators, New Zealand). The average relative humidity of the environment was converted to an equilibrium moisture concentration based on the sorption isotherm. The surface moisture content/water potential was obtained from Eq. (9), used to describe the final moisture concentration/water potential profile determined in the previous section.

\subsubsection{Diffusion coefficients}

Diffusion coefficients were estimated by fitting model predictions to experimental moisture profiles using a non-linear least squares procedure implemented in the MATLAB 6.0 programming environment (The Mathworks, Inc., Natick, USA), corresponding to the procedures outlined by Veraverbeke et al. (2003). In the two material approach (experiment 2), the diffusion coefficients of inner cortex and outer cortex tissues were estimated simultaneously in one simulation experiment.

In experiments 3 and 4, the diffusivity was obtained directly from fluxes measured over a certain area of isolated cuticle, to which Fick's first law applies. Due to a 
large expected internal resistance in comparison to an external one, the convection mass transfer coefficient was assumed to be infinity. The thickness of the cuticle was measured by means of light microscopy.

\section{Results and discussions}

\subsection{Moisture loss rates}

The water loss rate was determined from the weight loss of a pear tissue cylinder as function of time at $1{ }^{\circ} \mathrm{C}$ and $20^{\circ} \mathrm{C}$ and $80-90 \%$ relative humidity. At $1{ }^{\circ} \mathrm{C}$, the curves decreased very strongly at the beginning, which could be attributed to evaporation of excess water at the free surface of the samples and temperature stabilisation (Fig. 3a). At this stage, a large water evaporation rate was caused by the higher temperature and, hence, water vapour pressure of the sample surface (samples were prepared in the laboratory at $20^{\circ} \mathrm{C}$ ). The water loss rate quickly decreased until the sample reached to a stable temperature. The above phenomenon did not happen in the case of the experiment at $20^{\circ} \mathrm{C}$. This is because the stable temperature stage was already set as the beginning of the experiment. For the tissue, the weight loss rate decreased with time, indicating that steady state was not yet reached and constant rate drying did not occur. In this work, experiments were finished when weight loss reached approximately $5 \%$ of the initial sample weight. This is because that amount of weight loss fulfilled two criteria for coefficient estimation of a diffusion process. On the one hand, the moisture profiles of initial and dried samples could visually be distinguished. On the other hand, one is properly able to neglect a shrinkage problem of the tissue due to a massive moisture loss.

In Fig. 3b, experiments 3 and 4 gave more noisy data, which was due to disturbance of the air flow over a larger exposed surface of a sample. In case of weight loss for a cuticle or cuticle plus outer cortex tissue sample, the weight decreased linearly in time indicating a steady state of moisture flux through the sample, according to Fick's first law.

\subsection{Moisture concentration vs. water potential concentration profiles}

A typical water distribution profile, based on the moisture content on dried weight base inside the cylin-
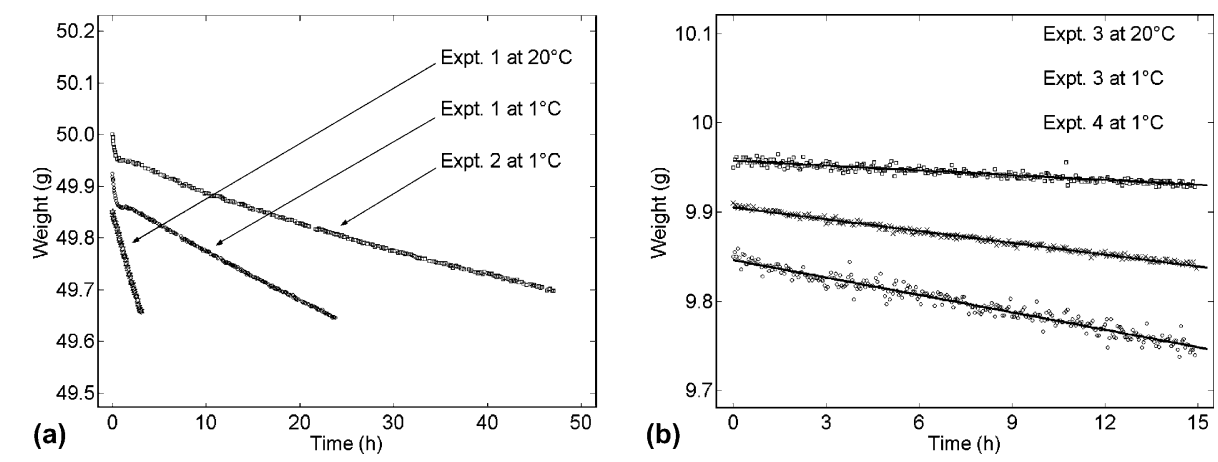

Fig. 3. Water loss rate of different experiments. At $1{ }^{\circ} \mathrm{C}$, the curves decreased strongly at the beginning due to evaporation of excess water at the free surface of the samples and temperature stabilisation (a). This did not happen with experiments at $20^{\circ} \mathrm{C}$. The weight loss rate decreases with time, indicating that steady state is not yet reached. In (b), the weight decreased linearly in time indicating a steady state of moisture flux through the sample, according to Fick's first law.
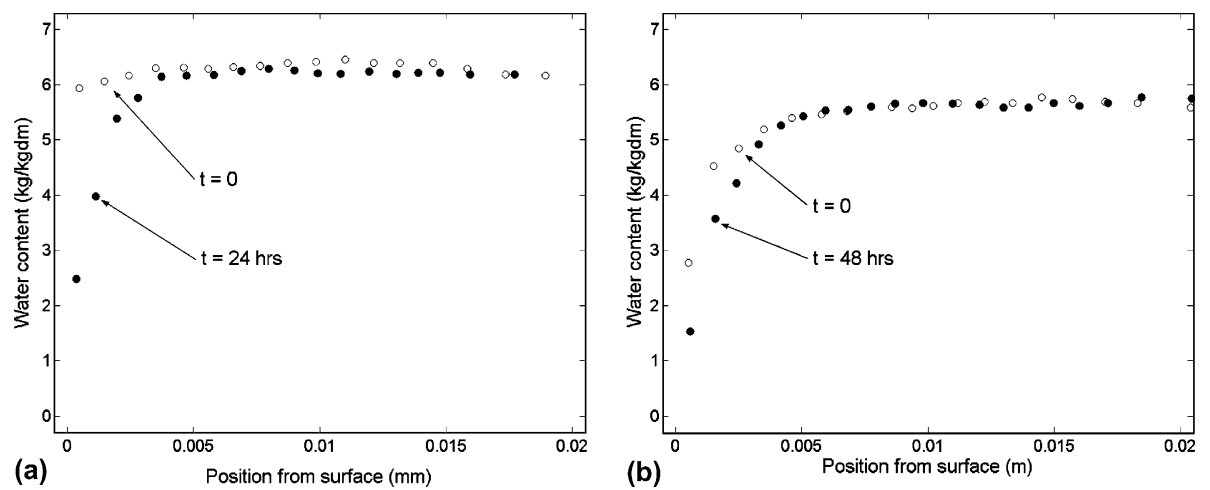

Fig. 4. Water concentration profile of inner cortex sample (a) and of sample with outer cortex (b) at the start $(t=0)$ and at the end $(t=24,48 \mathrm{~h})$ of the diffusion experiment. 

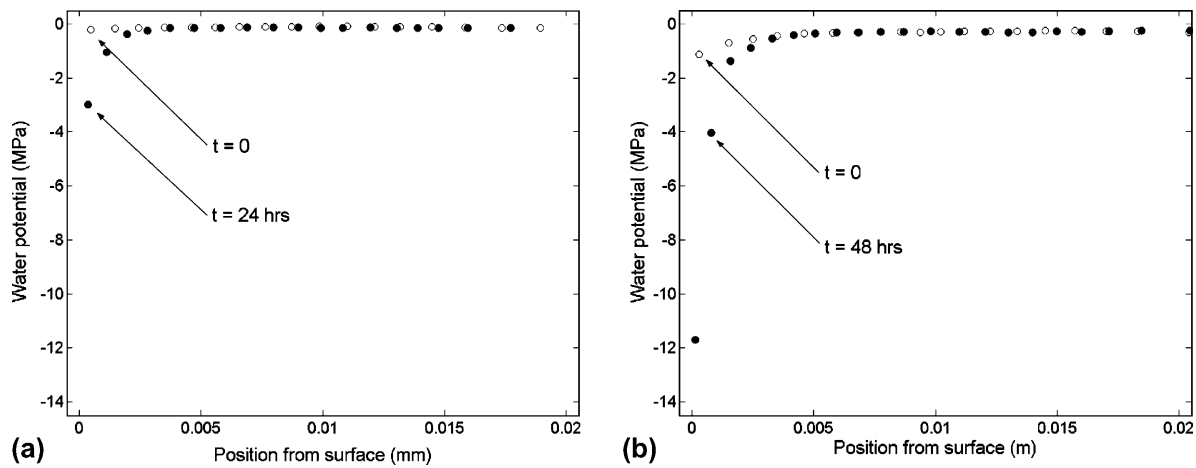

Fig. 5. Water potential profile of inner cortex sample (a) and of sample with outer cortex (b) at the start $(t=0)$ and at the end $(t=24,48 \mathrm{~h})$ of the diffusion experiment. In graph (b), the more negative water potential at surface indicates a larger internal water resistance to external water resistance ratio in sample with outer cortex.

drical samples at the start and at the end of the diffusion experiment, is shown in Fig. 4. The moisture concentration profile of the initial sample showed no appreciable water concentration gradient (Fig. 4a) while it had a considerable gradient in the case of the sample with inner and outer cortex tissue (Fig. 4b). Compared to an inner cortex sample (Fig. 4a, 24 h), the moisture distribution in a cylinder including outer cortex (Fig. 4b, $48 \mathrm{~h}$ ) after diffusion was in a different state with a smaller shift, while the drying time was longer. This suggested that the outer cortex layer has more resistance to water movement than inner cortex tissue.

The water content profile of inner cortex tissue-only sample was transformed into a water potential profile (Figs. 4a to 5a) by means of the inner cortex moisture isotherm while sorption isotherms of both outer and inner cortex were needed in case of the sample with outer cortex tissue (Figs. $4 \mathrm{~b}$ to $5 \mathrm{~b}$ ). Unlike the water concentration profile, the water potential in the initial samples in both cases were close to equilibrium, with a small gradient near the surface, explaining little water loss during the storage period. However, water potential gradients became significant after drying as a result of forced water removal from the tissue surface exposed to the air. It is also observed that the profile development was more significant for the inner cortex tissue compared to the sample including outer cortex, and this in a shorter time. It is clear that not water concentration but water potential, which is continuous across materials, is a better parameter to describe water movement in multi-material systems like pear fruit (Nguyen et al., 2004). In practice, it is commonly believed that the cuticle is the single barrier to water loss, neglecting gradients in the cortex tissue (Maguire et al., 1999). While this might hold for reduced water loss conditions (optimal storage, see the non-dried sample), at least in more extreme drying conditions (shelf life), the resistance of cortex tissue to water loss needs to be taken into account.

\subsection{Surface mass transfer coefficients}

Surface mass transfer coefficients were in the high range (from $10^{-8}$ to $10^{-7} \mathrm{~m} \mathrm{~s}^{-1}$ ) and the variation between different experimental conditions was large (about $25 \%$ ). This result can be explained as follows. First, fluctuation of the RH during the experiment caused a hysteresis, which changes the sorption isotherm characteristics of pear tissue at the surface of the samples. Second, biological variability among experimental pears, which led to the conversion of moisture content into a wrong corresponding water potential value, can also play a role. Third and final, an error in estimation of surface moisture content by fitting the experimental data can also make a contribution. Since our objective was diffusion properties of the tissue, this was not further explored.

\subsection{Diffusion coefficients}

\subsubsection{Picking date and storage time}

Diffusion coefficients were determined from moisture profiles relating water concentration and water potential to the position in the tissue cylinder. In Fig. 6a and b, the model predictions for the moisture distribution inside pear flesh match quite well the experimental data. For the experiment 1 (inner cortex sample), diffusion coefficients are listed in Table 1 (using water concentration) for the different experimental conditions. In our case, the diffusion coefficients decreased with storage time. However, this decrease was limited to the first months of storage. This could be due to the fact that at storage conditions when the intact pears lack a water source, cells have a mechanism to prevent the water loss of their own, which could affect the water transport process in the whole tissue. This mechanism only exists to some extent. At a certain critical point, when the biological changes are too severe, water will more easily transport in the tissue again. This phenomenon was present 

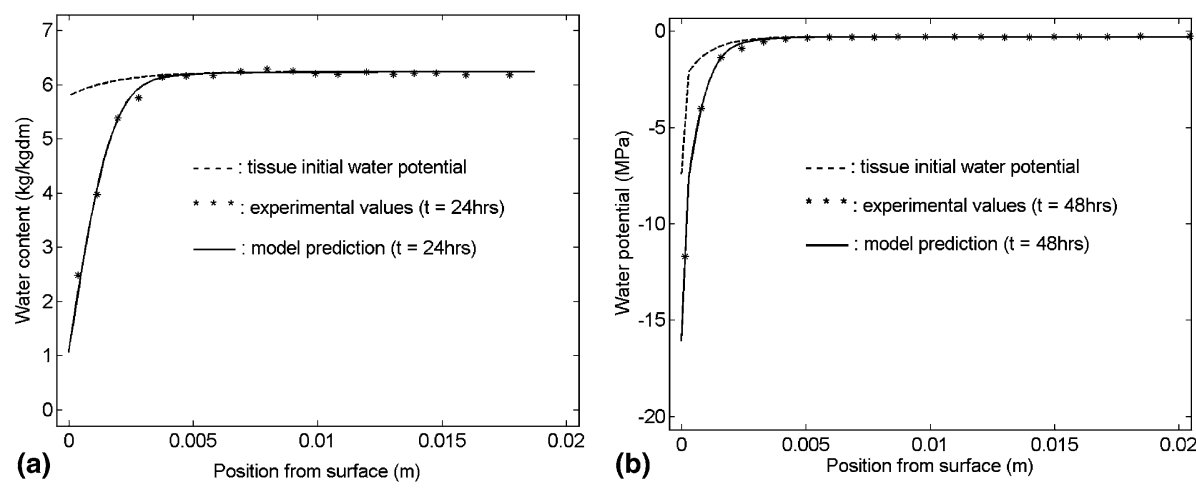

Fig. 6. Model vs. experiments at $1{ }^{\circ} \mathrm{C}$ : inner cortex sample (a) and sample with outer cortex tissue (b).

Table 1

Diffusion coefficients at $1{ }^{\circ} \mathrm{C}\left(D-10^{-13} \mathrm{~m}^{2} \mathrm{~s}^{-1}\right)$ obtained from experiments 1 and 2

\begin{tabular}{lclll}
\hline Storage time (months) & Experiment 1 & & Experiment 2 & \\
\cline { 2 - 2 } & Inner cortex & & Inner cortex & Outer cortex \\
\hline Early picking date & $120.9 \pm 20.5$ & $40.2 \pm 6.4$ & $5.9 \pm 0.7$ \\
1 & $78.7 \pm 20.4$ & $30.2 \pm 7.8$ & $5.7 \pm 1.6$ \\
4 & $70.6 \pm 5.2$ & $x$ & $x$ \\
7 & & & \\
Late picking date & $123.0 \pm 48.0$ & $45.8 \pm 7.7$ & $4.7 \pm 1.1$ \\
1 & $87.9 \pm 5.8$ & $55.4 \pm 23.0$ & $7.8 \pm 1.4$ \\
4 & $97.4 \pm 17.5$ & $x$ & $x$ \\
7 & & & \\
\hline
\end{tabular}

in case of late picking date pears (Table 1). For the early picking date, biological changes happened slower so the critical point was not yet reached. The increase of relative differences between the two picking dates could be a fact proving that biological changes happened faster in the late picking date pears than that in early picking date pears. The relative differences are $1.6 \%, 10 \%$ and $27 \%$ respectively for 1 -month, 4 -month and 7 -month storage pears.

Diffusion coefficients appeared to be slightly larger in case of late picking date pears. This could probably be understood by the more mature stage of late picking date pears than that of early picking date pears. Later picking dates may cause cell membrane degradation and, hence, an increase of the diffusion coefficients. However, a large biological variability was observed in the trials (high standard deviation values).

Diffusion coefficients for both inner and outer cortex were obtained from experiment 2 (sample with outer cortex tissue), and are also listed in Table 1 (using water potential). For the inner cortex tissue, the diffusion coefficients of late picking date pears were still slightly larger than those of early picking date pears. Diffusion coefficients from experiment 2, were 1.5 (late picking date, 4-month storage) to 3 (early picking date, 1-month storage) times smaller than those from experiment 1 . The reason for this difference is unclear. One reason may be that sample definition was arbitrary with respect to the distinction between outer and inner cortex. It was assumed that the first $0.3 \mathrm{~mm}$ was outer cortex. In reality, there is no clear distinction between outer and inner cortex (Schotsmans, 2003), therefore in our definition the outer layers of the inner cortex may have properties that decrease the diffusion coefficient as observed. In case of outer cortex tissue, there is no evidence that diffusion coefficients depended on storage period or picking date. Diffusion coefficients ranged from 4.7 to $7.8 \times$ $10^{-13} \mathrm{~m}^{2} \mathrm{~s}^{-1}$. These values were about 5 (early picking date, 4-month storage) to 10 (late picking date, 1-month storage) times smaller than those for inner cortex tissue (Table 1, experiment 2). The small diffusion coefficients of outer cortex tissue indicated the inherent protection property of the near skin layers against water loss.

Solving experiment 1 in term of water potential resulted in the same diffusion coefficients compared to the water concentration formulation.

\subsubsection{Temperature}

Diffusion coefficients for inner and outer cortex tissue were also obtained after shelf life (Table 2). For these experiments, only pears harvested at commercial picking date and stored for 1 month were investigated. The values of firmness and sugar content in Table 2 are averages of 30 measurements performed on 15 fruits for each shelf life day. It is shown that the sugar content did not change much but large firmness losses were

Table 2

Diffusion coefficients at $20^{\circ} \mathrm{C}\left(D-10^{-13} \mathrm{~m}^{2} \mathrm{~s}^{-1}\right)$ obtained from experiments 1 and 2

\begin{tabular}{|c|c|c|c|c|c|}
\hline \multirow{2}{*}{$\begin{array}{l}\text { Shelf } \\
\text { life } \\
\text { (days) }\end{array}$} & \multirow{2}{*}{$\begin{array}{l}\text { Sugar } \\
\text { content } \\
\text { (Brix) }\end{array}$} & \multirow{2}{*}{$\begin{array}{l}\text { Firmness } \\
\text { (N) }\end{array}$} & \multirow{2}{*}{$\frac{\text { Experiment } 1}{\text { Inner }}$} & \multicolumn{2}{|l|}{ Experiment 2} \\
\hline & & & & Inner & Outer \\
\hline 1 & 14.86 & 115.69 & $435.9 \pm 108.0$ & $386.1 \pm 79.7$ & $10.5 \pm 1.5$ \\
\hline 3 & 15.27 & 79.19 & $819.3 \pm 251.0$ & $x$ & $x$ \\
\hline 5 & 15.39 & 30.29 & $904.7 \pm 196.8$ & $x$ & $x$ \\
\hline 7 & 15.16 & 17.21 & $x$ & $x$ & $x$ \\
\hline
\end{tabular}


observed. This helps explain why the diffusion coefficients increased considerably (from 435.9 to $904.7 \times$ $10^{-13} \mathrm{~m}^{2} \mathrm{~s}^{-1}$ ) during shelf life. After day 5 , tissue became very soft, which made it difficult to slice samples as well as measuring slice thickness. So shelf life was carried out until day 5 with experiment 1 . For experiment 2 , after more than 1 day in shelf life, it was impossible to remove the cuticle from the sample surface without a serious damage, so only one experiment after 1-day shelf life was implemented.

Comparing diffusion coefficients at $1^{\circ} \mathrm{C}$ (Table 1,1 month storage) and at $20^{\circ} \mathrm{C}$ (Table 2, 1-day shelf life), one can notice that the storage temperature has a great effect on the moisture diffusion process. For experiment 1 , the diffusion coefficient increased about 3.6 times when temperature increased from $1{ }^{\circ} \mathrm{C}$ to $20^{\circ} \mathrm{C}$. For experiment 2 , the diffusion coefficient increased 9.6 times (early picked) and 8.4 times (late picked) in the case of inner cortex tissue while it increased only by a factor 2 in the case of outer cortex tissue. The smaller increase in diffusion coefficients of outer cortex tissue indicates again the inherent protection property of the near skin layers against temperature variation of the environment.

\subsubsection{Tissues}

In Table 3 , diffusion coefficients of cuticle at $1{ }^{\circ} \mathrm{C}$ and $20{ }^{\circ} \mathrm{C}$ are presented. For these experiments ( 3 and 4 ), the average thickness was $17.5 \pm 1(\mu \mathrm{m})$ measured by means of a light microscopy (Trino Topic T, CETI, Antwerp, Belgium) and the dry matter density was $1111 \pm 80$ $\left(\mathrm{kg} \mathrm{m}^{-3}\right)$. For experiment 3, the sample thickness was measured by means of a stereomicroscope (SMZ1000, Nikon, Japan) and the diffusion coefficient of the outer cortex tissue was taken from experiment 2 , and was equal $5.3 \times 10^{-13} \mathrm{~m}^{2} \mathrm{~s}^{-1}$ in the case of $1{ }^{\circ} \mathrm{C}$ (average of early and late picking date after 1 -month storage) and $10.5 \times 10^{-13} \mathrm{~m}^{2} \mathrm{~s}^{-1}$ in the case of $20^{\circ} \mathrm{C}$. In general, the diffusion coefficient of cuticles was significantly lower

Table 3

Diffusion coefficients for the cuticle $\left(D-10^{-13} \mathrm{~m}^{2} \mathrm{~s}^{-1}\right)$ obtained from experiments 3 and $4\left(d_{\text {cuticle }}=17.5 \mu \mathrm{m} ; \rho_{\text {cuticle }}=1111 \mathrm{~kg} / \mathrm{m}^{3}\right)$

\begin{tabular}{lll}
\hline Conditions & Material properties & Diffusivity \\
\hline Experiment 4 & & \\
- RH $=94 \% \pm 2 \%$ & $\bullet d=17.5 \pm 1(\mu \mathrm{m})$ & $1.10-1.20$ \\
- $T=1{ }^{\circ} \mathrm{C}$ & $\bullet \rho=1111 \pm 80\left(\mathrm{~kg} / \mathrm{m}^{3}\right)$ & \\
- $h=\infty$ & & \\
Experiment 3 & & \\
- RH $=75.6 \%$ & $\bullet d=300 \pm 48(\mu \mathrm{m})$ & \\
- $T=1{ }^{\circ} \mathrm{C}$ & $\bullet \rho_{\text {outer cortex }}=263.76 \pm\left(\mathrm{kg}^{\circ} \mathrm{m}^{3}\right)$ & \\
- $h=\infty$ & $\bullet D_{\text {outer cortex }}=5.3 \times 10^{-13} \mathrm{~m}^{2} \mathrm{~s}^{-1}$ & \\
Experiment 3 & & \\
- RH $=75.9 \%$ & $\bullet d=350 \pm 46(\mu \mathrm{m})$ & \\
- $T=20^{\circ} \mathrm{C}$ & $\bullet \rho_{\text {outer cortex }}=263.76 \pm\left(\mathrm{kg} / \mathrm{m}^{3}\right)$ & \\
- $h=\infty$ & $\bullet D_{\text {outer cortex }}=10.5 \times 10^{-13} \mathrm{~m}^{2} \mathrm{~s}^{-1}$ & \\
\hline
\end{tabular}

than that of cortex tissue and was in the same range as obtained for apple cuticle (Veraverbeke et al., 2003). However, at the same temperature $\left(1{ }^{\circ} \mathrm{C}\right)$, experiment 4 gave a larger diffusion coefficient than that of experiment 3 . This could be explained by presence of some holes on a cuticle sample which could not be recognised macroscopically. One should bear in mind that, in experiment 4 , it was very difficult to isolate a cuticle sample without any damage. Therefore, experiment 3 was believed to be more reliable, as the intact structure of cuticle and outer cortex was investigated.

For the cuticle, the effect of temperature on the moisture transport was also noticed. The diffusion coefficient more than doubled when temperature increased from $1{ }^{\circ} \mathrm{C} \quad\left(D=0.55 \times 10^{-13} \mathrm{~m}^{2} \mathrm{~s}^{-1}\right)$ to $20^{\circ} \mathrm{C} \quad(D=1.28 \times$ $\left.10^{-13} \mathrm{~m}^{2} \mathrm{~s}^{-1}\right)$.

\section{Conclusions}

With the diffusion model and set-up established, it was possible to determine apparent diffusion coefficients of different tissues (outer cortex, inner cortex) and cuticle of pears. For the first time, diffusion coefficients of different tissues of an intact pear were directly determined. The values found were comparable with those in literature obtained with other techniques and for other horticultural products with more or less the same structure such as apple. For multi-material systems like pear fruit, it is better to use water potential but not water concentration to describe water status as well as water movement.

Storage time and picking date showed little effect on moisture transport in outer cortex but not in case of inner cortex. The diffusion coefficients decreased with storage time while a later picking date caused a loss in water resistance. However, a large biological variability was observed. A large effect of storage temperature on moisture diffusion process was observed. Diffusion coefficients increased by a factor 10,2 and more than 2 respectively in case of inner cortex, outer cortex and cuticle when temperature increased from $1{ }^{\circ} \mathrm{C}$ to $20^{\circ} \mathrm{C}$. The smaller increase in diffusion coefficients of outer cortex and cuticle indicated the protection property of the near skin layers as well as the skin against temperature variation of the environment. For different tissues, it was found that diffusion coefficients reduced dramatically from inner cortex to outer cortex and cuticle. The high water resistance of outer cortex and cuticle explained the inherent property of these layers against water loss.

In future work the assessment of a larger dataset to include biological variability will be addressed. To validate the model, simulation of a drying process of a whole intact pear will be carried out by implementing the model in 3-D and comparing the predicted moisture 
distribution of each experimental pear to that obtained by a non-destructive technique like magnetic resonance imaging. Finally, the apparent diffusion coefficients will be used for detailed modelling and prediction of water transport in whole pears at different storage conditions.

\section{Acknowledgement}

The authors would like to acknowledge the Catholic University of Leuven (IRO scholarship). Acknowledgement is extended to the Belgian Ministry of Small Enterprises, Traders and Agriculture (project S-6056), the Research Council of the Catholic University of Leuven (project IDO 00/008) and the Flemish Fund for Scientific Research (project G. 0200.02). Pieter Verboven is postdoctoral researcher with the Flemish Fund for Scientific Research (F.W.O_-Vlaanderen).

\section{References}

Anonymous. (2003). Jaarverslag 2002. (E: Year Report 2002). Flemish Center of Postharvest Technology, Leuven, Belgium, p. 12.

Crank, J. (1975). The mathematics of diffusion. London: Oxford University Press.

Datta, A. K. (Ed.). (2002). Biological and bioenvironmental heat and mass transfer. New York: Marcel Dekker.

Datta, A. K., \& Zhang, J. (Eds.). (1999). Porous media approach to heat and mass transfer in solid foods. Department of Agriculture And Biology Engineering, Cornell University.

Doulia, D., Tzia, K., \& Gekas, V. (2000). A knowledge base for the apparent mass diffusion coefficient (DEFF) of foods. International Journal of Food Properties, 3(1), 1-14.

Finkelstein, A. (Ed.). (1987). Water movement through lipid bilayers, pores and plasma membranes; theory and reality. New York: Wiley.

Gou, P., Mulet, A., Comaposada, J., Benedito, J., \& Arnau, J. (1996). Water diffusion in dry cured ham. In Proceeding of 10th international drying symposium, vol. (B), July 2-August 2, Krakow, Poland (pp. 778-784).

Gros, J. B., \& Ruegg, M. (1987). In R. Jowitt, F. Escher, M. Kent, B. McKenna, \& M. Roques (Eds.), Physical properties of foods-2.
Proceedings of COST90bis project (pp. 71). London: Elsevier Applied Science.

Maguire, K. M., Lang, A., Banks, N. H., Hall, A., Hopcroft, D., \& Bennett, R. (1999). Relationship between water vapour permeance of apples and microcracking of the cuticle. Journal of Postharvest Biology and Technology, 17, 89-96.

Merva, G. E. (1995). Physical principles of the plant system. Michigan, USA: American Society of Agricultural Engineering.

Nguyen, T. A., Verboven, P., Daudin, J. D., Vandewalle, S., \& Nicolaï, B. M. (2004). Effect of picking date, time and temperature on water sorption of conference pear tissue. Postharvest Biology and Technology, 33(3), 243-253.

Nguyen, T. A., Verboven, P., Scheerlinck, N., Veraverbeke, E., \& Nicolaï, B. M. (2002). An estimation procedure of effective diffusivity in pear tissue by means of a numerical water diffusion model. In B. E. Verlinden (Ed.). Proceedings of the International conference on Postharvest Unlimited, 11-14 June 2002, Leuven, Belgium (pp. 541-548).

Nobel, P. S. (Ed.). (1991). Physicochemical and environmental plant physiology. New York: Academic Press.

Ruiz-Cabrera, M. A., Gou, P., Foucat, L., Renou, J. P., \& Daudin, J. D. (2004). Water transfer analysis in port meat supported by NMR imaging. Meat Science, 67(1), 169-178.

Schotsmans, W. (2003). Gas diffusion properties of Pome fruit in relation to storage potential $(186 \mathrm{p}) . \mathrm{PhD}$ thesis, K.U. Leuven, Belgium.

Segerlind, L. (Ed.). (1984). Applied finite element analysis. New York: John Wiley \& Sons.

Veraverbeke, E., Verboven, P., Scheerlinck, N., Hoang, M. L., \& Nicolaï, B. M. (2003). Determination of the diffusion coefficient of tissue, cuticle, cutin and wax of apple. Journal of Food Engineering, 58, 285-294.

Verstreken, E., Van Hecke, P., Scheerlinck, N., De Baerdemaeker, J., \& Nicolaï, B. (1998). Parameter estimation for moisture transport in apples with the aid of NMR imaging. Magnetic Resonance in Chemistry, 36, 196-204.

Zogzas, N. P., \& Maroulis, Z. B. (1994). Moisture diffusivity methods of experimental determination-a review. Drying Technology, 12(3), 483-515.

Zogzas, N. P., \& Maroulis, Z. B. (1996). Effective moisture diffusivity estimation from drying data. Comparison between various methods of analysis. Drying Technology, 14(7\&8), $1543-1573$.

Zogzas, N. P., Maroulis, Z. B., \& Marinos-Kouris, D. (1996). Moisture diffusivity data compilation in foodstuffs. Drying Technology, 14(10), 2225-2253. 